\title{
Epidemiology of Hospitalized Traumatic Pelvic Fractures and Their Combined Injuries in Taiwan: 2000-2011 National Health Insurance Data Surveillance
}

\author{
Nan-Ping Yang, ${ }^{1,2}$ Chien-Lung Chan, ${ }^{3}$ Dachen Chu, ${ }^{2,4}$ Yu-Zhen Lin, ${ }^{3}$ Kai-Biao Lin, ${ }^{3,5}$ \\ Ching-Shao Yu, ${ }^{1,6}$ I-Liang Yu, ${ }^{1}$ Nien-Tzu Chang, ${ }^{7}$ and Yi-Hui Lee ${ }^{7,8}$ \\ ${ }^{1}$ Department of Orthopedic Surgery, Taoyuan General Hospital, Ministry of Health \& Welfare, Taoyuan 33004, Taiwan \\ ${ }^{2}$ Institute of Public Health, National Yang-Ming University, Taipei 11221, Taiwan \\ ${ }^{3}$ Department of Information Management, Yuan Ze University, Taoyuan 32003, Taiwan \\ ${ }^{4}$ Department of Neurologic Surgery, Taipei City Hospital, Taipei 10341, Taiwan \\ ${ }^{5}$ Department of Computer Science and Technology, Xiamen University of Technology, Xiamen 361024, China \\ ${ }^{6}$ Department of Orthopedic Surgery, National Taiwan University Hospital, Taipei 10048, Taiwan \\ ${ }^{7}$ Department of Nursing, College of Medicine, National Taiwan University, Taipei 10617, Taiwan \\ ${ }^{8}$ Department of Nursing, School of Nursing, Chang Gang University, Taoyuan 33302, Taiwan
}

Correspondence should be addressed to Nan-Ping Yang; yang.nanping@gmail.com

Received 21 December 2013; Revised 26 February 2014; Accepted 2 March 2014; Published 1 April 2014

Academic Editor: Patrick Schober

Copyright (C) 2014 Nan-Ping Yang et al. This is an open access article distributed under the Creative Commons Attribution License, which permits unrestricted use, distribution, and reproduction in any medium, provided the original work is properly cited.

\begin{abstract}
Background. From the viewpoint of prehospital emergency medicine, a greater proportion of pelvic fractures not of a life-threatening status but combined with other injuries need more comprehensive recognition. Methods. A 12-year nationwide health database of inpatients was reviewed. All cases diagnosed as pelvic fractures were enrolled. The associated injuries classified into 20 categories were further analyzed. Results. During 2000-2011, the hospitalized incidence of pelvic fractures in Taiwan ranged from 17.17 to 19.42 per 100,000, and an increasing trend with age was observed. The mean case-fatality rate was $1.6 \%$ for females and $2.1 \%$ for males; male patients with pelvic fractures had a significantly higher risk of death than female patients after adjusting for other covariates. $74.2 \%$ of these cases were combined with other injuries. The most common associated injuries in an identified body region were other orthopedic fractures of the lower limbs (21.50\%), spine/trunk (20.97\%), or upper limbs (18.18\%), followed by significant head injuries (17.59\%), intra-abdominal injuries (11.00\%), and thoracic injuries (7.20\%). Conclusion. The incidence of hospitalized pelvic fractures in Taiwan was low and the case-fatality rate was lower than those of other countries. Concurrently, coexistence of major combined injuries with pelvic fractures was easily treated at medical centers.
\end{abstract}

\section{Introduction}

Pelvic or acetabular fractures are rare injuries $(3-8 \%)[1,2]$ as compared with fractures in other body regions. They are accompanied by a high mortality (4-28\%) [1,3-6]. Most deaths in patients with pelvic fractures are not caused by the pelvic fracture itself but are linked to associated injuries $[1,3]$. Fatal pelvic injury patients die at a median of 2 days after the trauma [5]. There are significant similarities between pediatric and adult patients with pelvic injuries; the incidences of associated abdominal injuries and the mortality rate of children do not differ from those of adults [1,7]. A meta-analysis consisting of twelve studies with a total of 5,454 pelvic fracture patients concluded that in stable and alert trauma patients a thorough clinical examination will detect pelvic fractures with nearly $100 \%$ sensitivity, thus rendering initial radiography unnecessary in this group of patients [8].

From the viewpoint of prehospital emergency medical management for injured people, identification of pelvic fractures in those with stable or unstable vital signs is critical. Furthermore, evaluation of possible associated injuries is still important even though the greater proportion of pelvic 
fractures are not of a life-threatening status. Comprehensive epidemiologic surveillance of pelvic fractures with other combined injuries could provide sufficient information to prehospital or inhospital medical staff to improve emergency management and enable policymakers to consider alternative resources and training programs.

In Taiwan, an epidemiological survey using the nationwide randomly sampled database showed that $26.4 \%$ of all emergency department (ED) visitors utilized ED services due to injury or poisoning [9]. An emergency-critical hierarchical system (3 levels) was established in Taiwan in 2009. Up to April, 2011, there were 23 highest-level hospitals and 35 midlevel hospitals accredited in Taiwan [10]. Using evidence based on Taiwan's nationwide registered health data, the purposes of the present study were to investigate (1) the incidence and mortality of hospitalized traumatic pelvic fractures in Taiwan, (2) the distributions of other injuries combined with these traumatic pelvic fractures, and (3) factors influencing the pattern of major combined injuries, inhospital mortality and those treated at medical centers among these hospitalized pelvic fractures.

\section{Methods}

2.1. Data Resources. From 1995 to 2011, 23.199 million citizens were enrolled in the single-payer National Health Insurance (NHI) program, reaching $99.88 \%$ of the total population of Taiwan. This Taiwan universal national health insurance, financed jointly by payroll taxes, subsidies, and individual premiums, has consistently received a 70 percent public satisfaction rate [11]. The nationwide data analyzed in this research were obtained from the National Health Insurance Research Database (NHIRD), which is maintained by the Bureau of National Health Insurance (BNHI) and the National Health Research Institute (NHRI) for research purposes. The academic databank of the NHIRD includes various subdatasets, for example, inpatient expenditures by admissions (DD), details of inpatient orders (DO), ambulatory care expenditures by visits (CD), and details of ambulatory care orders (OO). In this study, the DD dataset was used for further analysis.

2.2. Data Protection and Permission. The NHIRD cannot be used to identify patients' personal information; hence, all datasets have already undergone a scrambling procedure before being sent to the NHRI for personal information protection. Essentially, it is impossible to restore the original data when using this database. Moreover, researchers who use the NHIRD are required to declare that they have no intention to obtain information that could potentially violate the privacy of patients or care providers. This study was approved by the Institutional Review Board (IRB) of Taoyuan General Hospital, which has been certified by the Ministry of Health \& Welfare, Taiwan (IRB Approval Number: TYGH101049), and the protocol was evaluated by the NHRI, who gave their agreement to this planned analysis of the NHIRD (Agreement Number: NHIRD-101-566).
TABLE 1: Definitions of 20 categories of injuries combined with pelvic fractures*.

\begin{tabular}{|c|c|c|}
\hline Group & $\begin{array}{l}\text { ICD9-CM } \\
\text { codes }\end{array}$ & Description \\
\hline 1 & $\begin{array}{l}800-804 \\
850-854\end{array}$ & Fracture of skull (intracranial injury) \\
\hline 2 & $805-809^{* *}$ & Fracture of spine and trunk \\
\hline 3 & $810-819$ & Fracture of upper limb \\
\hline 4 & $820-829$ & Fracture of lower limb \\
\hline 5 & $830-839$ & Dislocation \\
\hline 6 & $840-848$ & $\begin{array}{l}\text { Sprains and strains of joints and adjacent } \\
\text { muscles }\end{array}$ \\
\hline 7 & $860-862$ & Internal injury of chest \\
\hline 8 & $863-869$ & Internal injury of abdomen and pelvis \\
\hline 9 & $870-879$ & Open wound of head, neck, and trunk \\
\hline 10 & $880-887$ & Open wound of upper limb \\
\hline 11 & $890-897$ & Open wound of lower limb \\
\hline 12 & $900-904$ & Injury to blood vessels \\
\hline 13 & $905-909$ & $\begin{array}{l}\text { Late effects of injuries and other external } \\
\text { causes }\end{array}$ \\
\hline 14 & 910-919 & Superficial injury \\
\hline 15 & $920-924$ & Contusion with intact skin surface \\
\hline 16 & $925-929$ & Crush injuries \\
\hline 17 & $930-939$ & $\begin{array}{l}\text { Effects of foreign body entering through } \\
\text { orifice }\end{array}$ \\
\hline 18 & $940-949$ & Burns \\
\hline 19 & $950-957$ & Injury to nerves and spinal cord \\
\hline 20 & $958-959$ & $\begin{array}{l}\text { Certain traumatic complications and } \\
\text { unspecified injuries }\end{array}$ \\
\hline
\end{tabular}

${ }^{*}$ Pelvic fracture series (ICD9-CM coded as 808.X).

${ }^{* *}$ Group 2 associated injuries excluded pelvic fracture series.

2.3. Data Selection and Definition. In this study, we focused on the population hospitalized due to pelvic fractures, with any other combined injuries or without, data of which were obtained from the nationwide inpatient expenditures by admissions (DD) dataset of the NHIRD between January 1, 2000, and December 31, 2011. All patients meeting the criteria of pelvic fracture with an International Classification of Diseases, 9th Revision, Clinical Modification (ICD9-CM) diagnosis code recorded as 808.X (i.e., 808.0 808.9) were enrolled.

In order to investigate the contribution of categorical diagnoses of associated injuries, 20 groups of ICD9-CM diagnosis codes were evaluated [12]. Thus, combined injuries were defined as (Table 1) fracture of the skull, intracranial injury (800-804, 850-854 series), fracture of the spine and trunk (805-809 series), fracture of upper limbs (810-819 series), fracture of lower limbs (820-829 series), dislocation (830-839 series), sprains and strains of joints and adjacent muscles (840-848 series), internal injury of the chest (860862 series), internal injury of the abdomen and pelvis (863869 series), open wound of the head, neck, and trunk (870879 series), open wound of upper limbs (880-887 series), open wound of lower limbs (890-897 series), injury to blood 
TABLE 2: Basic characteristics of cases hospitalized for pelvic fractures in Taiwan, 2000-2011.

\begin{tabular}{|c|c|c|c|c|c|c|c|c|c|c|c|}
\hline Year & $\begin{array}{l}\text { Total } \\
\text { cases }^{\mathrm{a}}\end{array}$ & Total residents ${ }^{\mathrm{b}}$ & $\begin{array}{c}\text { Crude } \\
\text { incidence }{ }^{c *}\end{array}$ & Male & Female & $<18$ years & $\begin{array}{c}18-29.9 \\
\text { years }\end{array}$ & $\begin{array}{c}30-49.9 \\
\text { years }\end{array}$ & $\begin{array}{c}50-64.9 \\
\text { years }\end{array}$ & $\begin{array}{c}65-74.9 \\
\text { years }\end{array}$ & $\begin{array}{l}75 \text { years } \\
\text { or more }\end{array}$ \\
\hline & & & & Incidence & Incidence & Incidence & Incidence & Incidence & Incidence & Incidence & Incidence \\
\hline 2000 & 4128 & $22,276,672$ & 18.53 & 17.33 & 19.39 & 4.38 & 20.85 & 17.31 & 25.46 & 37.53 & 74.75 \\
\hline 2001 & 4030 & $22,405,568$ & 17.99 & 16.17 & 19.44 & 4.33 & 20.44 & 16.24 & 24.75 & 37.28 & 67.08 \\
\hline 2002 & 4001 & $22,520,776$ & 17.77 & 15.95 & 19.22 & 4.13 & 19.99 & 15.86 & 23.52 & 36.69 & 67.61 \\
\hline 2003 & 3928 & $22,604,550$ & 17.38 & 15.81 & 18.59 & 3.79 & 19.67 & 15.01 & 23.17 & 33.22 & 69.34 \\
\hline 2004 & 4406 & $22,689,122$ & 19.42 & 17.62 & 21.13 & 4.04 & 22.25 & 16.71 & 24.97 & 40.39 & 70.51 \\
\hline 2005 & 4384 & $22,770,383$ & 19.25 & 17.73 & 20.82 & 4.02 & 21.55 & 16.48 & 24.92 & 36.95 & 71.13 \\
\hline 2006 & 4259 & $22,876,527$ & 18.62 & 17.21 & 20.06 & 4.68 & 19.22 & 15.46 & 23.39 & 40.11 & 66.66 \\
\hline 2007 & 4022 & $22,958,360$ & 17.52 & 15.52 & 19.56 & 4.20 & 18.73 & 13.33 & 21.41 & 36.26 & 70.40 \\
\hline 2008 & 3956 & $23,037,031$ & 17.17 & 15.67 & 18.70 & 3.70 & 18.27 & 12.89 & 21.12 & 36.44 & 66.59 \\
\hline 2009 & 3985 & $23,119,772$ & 17.24 & 15.13 & 19.37 & 3.33 & 18.85 & 12.22 & 21.88 & 36.79 & 64.72 \\
\hline 2010 & 4025 & $23,162,123$ & 17.38 & 15.43 & 19.35 & 3.72 & 17.47 & 13.75 & 20.36 & 33.92 & 66.32 \\
\hline 2011 & 4176 & $23,224,912$ & 17.98 & 16.50 & 19.47 & 3.62 & 19.07 & 13.38 & 20.07 & 37.07 & 69.68 \\
\hline
\end{tabular}

$\mathrm{c}=\mathrm{a} / \mathrm{b} ;{ }^{*} 1 / 100,000$.

vessels (900-904 series), late effects of injuries and other external causes (905-909 series), superficial injury (910-919 series), contusion with an intact skin surface (920-924 series), crush injuries (925-929 series), effects of a foreign body entering through an orifice (930-939 series), burns (940-949 series), injury to nerves and the spinal cord (950-957 series), and certain traumatic complications and unspecified injuries (958-959 series).

The pelvic fracture series (ICD9-CM coded as 808.X) was divided into 3 subtypes: (a) acetabulum fracture (coded as $808.0,808.1$ ) or multiple injuries with disruption of the pelvic ring (coded as 808.43, 808.53); (b) fracture of the pubis (coded as $808.2,808.3$ ), fracture of the ilium (coded as 808.41, 808.51), or fracture of the ischium (coded as 808.42, 808.52); and (c) others (coded as 808.49, 808.59, 808.8, and 808.9). In order to calculate the operative rate of these pelvic fractures, the ICD9-CM treatment codes were also evaluated.

To evaluate the case-fatality rate of hospitalized pelvic fractures in Taiwan, the mortality of the studied cases was defined as a discharge status coded as died. To evaluate the socioeconomic effect, the enrolled subjects were divided into normal population and low-income population, who must meet the criteria of Taiwan's Social Assistance Act, and were registered in Taiwan's NHI databank.

2.4. Statistics. In the analysis in this study, descriptive statistics comparing baseline characteristics were represented by the numbers of cases, percentages, and incidence with the 95\% Confidence Interval (CI). Means with Standard Deviation (SD) and Analysis of Variance (ANOVA) were used to describe and compare continuous variables among different subgroups. The significance was set at $P=0.05$. To evaluate the risk factors of major combined injuries, inhospital mortality and those treated in medical centers among these hospitalized pelvic fractures, multiple logistic regression method was used and Adjusted Odds Ratio (AOR) was calculated. Multilevel analysis (or the hierarchical linear modeling method, HLM method) was used as an analytical strategy, allowing examination of group-level and individuallevel factors [13]. The hypothesis and formula of HLM analysis in the present study were shown below as follows.

Level 1 HLM Model

$$
\begin{aligned}
Y_{i j}= & \beta_{0}+\beta_{1} *(\text { Age })+\beta_{2} *(\text { Group }-1) \\
& +\beta_{3} *(\text { Group }-2)+\beta_{4} *(\text { Group }-3) \\
& +\beta_{5} *(\text { Group }-4)+\beta_{6} *(\text { Group }-7) \\
& +\beta_{7} *(\text { Group }-8)+\beta_{8} *(\text { Group-others }) \\
& +\beta_{9} *(\text { Gender })+\gamma .
\end{aligned}
$$

Level 2 HLM Model

$$
\begin{aligned}
\beta_{0}= & \gamma_{00}+\gamma_{01} *\left(\text { hospital }_{\text {-regional }}\right) \\
& +\gamma_{02} *\left(\text { hospital }_{\text {-medical-center }}\right)+\mu_{0} .
\end{aligned}
$$

All statistical analyses were performed using the Statistical Package for Social Sciences for Windows (SPSS for Windows 18.0).

\section{Results}

The hospitalized incidence of pelvic fractures in Taiwan ranged from 17.17 to 19.42 per 100,000 during 2000-2011. Females had a higher incidence than males, and the elderly (aged 65 years or more) were noted to have a significantly increased incidence (Table 2). In total, there were 49,300 incident cases during the 12 -year study period enrolled in the present study.

Figure 1 shows the distribution of causes of traumatic pelvic fractures in the enrolled inpatients. In summary, $62 \%$ of the recorded cases resulted from transport accidents and $10 \%$ from falling accidents. Figure 2 shows a dynamic trend of 
TABle 3: Descriptions of the top 10 major injuries associated with hospitalized pelvic fracture cases in Taiwan.

\begin{tabular}{|c|c|c|c|c|c|c|}
\hline \multirow{2}{*}{$\begin{array}{l}\text { Categorical diagnoses of combined } \\
\text { injuries (grouping) }\end{array}$} & \multicolumn{3}{|c|}{ Summed cases in $2000-2011$} & \multirow{2}{*}{$\begin{array}{c}\text { Cumulative } \\
\text { incidence in general } \\
\text { Percentage } \\
(95 \% \mathrm{CI})\end{array}$} & \multirow{2}{*}{$\begin{array}{c}\text { Cumulative } \\
\text { incidence in males } \\
\text { Percentage } \\
(95 \% \mathrm{CI})\end{array}$} & \multirow{2}{*}{$\begin{array}{c}\text { Cumulative incidence } \\
\text { in females } \\
\text { Percentage } \\
(95 \% \mathrm{CI})\end{array}$} \\
\hline & Number & le $(\%)$ & Female & & & \\
\hline (4) Fract & & & & $21.50(21.13-21.86)$ & $25.23(24.66-25.79)$ & $18.49(18.02-18.96)$ \\
\hline (2) $\mathrm{Fr}$ & 10340 & 49.61 & & $20.97(20.62-21.33)$ & $22.59(22.04-23.13)$ & $19.66(1)$ \\
\hline & & & & & & \\
\hline & & & & & & \\
\hline (1) Fracture c & & & & & & \\
\hline (9) Open & 6243 & & & $12.66(12.37-12.96)$ & & $10.50(10.13-10.86)$ \\
\hline (14) Superficia & 5789 & & 57.33 & $11.74(11.46-12.03)$ & $10.85(10.45-11.26)$ & $12.50(12.10-12.90)$ \\
\hline (8) Internal injury of abdomen and pelvis & 5421 & & & $11.00(10.72-11.27)$ & $14.82(14.36-15.29)$ & $7.67(7.35-7.99)$ \\
\hline $\begin{array}{l}\text { (20) Certain traumatic complications and } \\
\text { unspecified injuries }\end{array}$ & 3830 & 48.82 & 51.18 & $7.77(7.53-8.01)$ & $8.23(7.87-8.59)$ & $7.39(7.08-7.71)$ \\
\hline (7) Internal injury of chest & 3551 & 60.12 & 39.88 & $7.20(6.98-7.43)$ & $9.40(9.02-9.78)$ & $5.34(5.07-5.61)$ \\
\hline
\end{tabular}

CI: confidence interval.

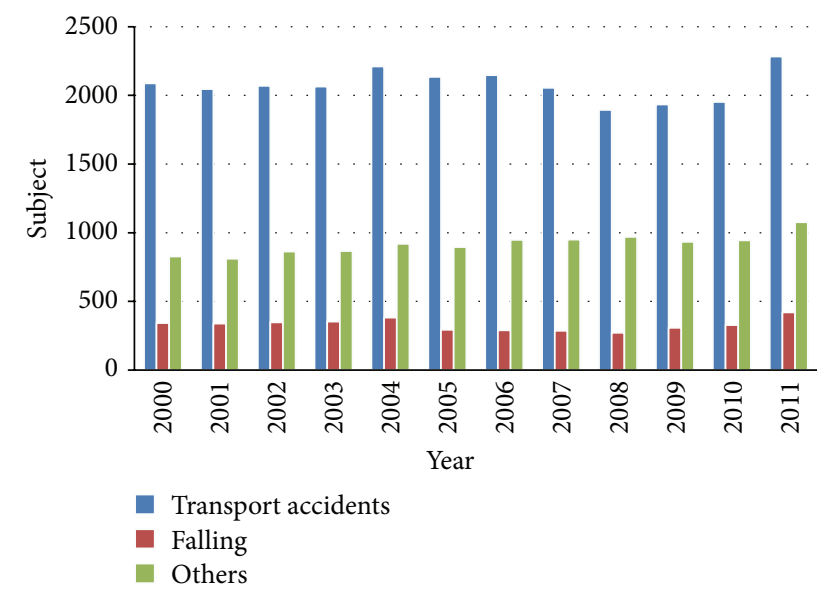

Figure 1: Annual causes of traumatic pelvic fractures admitted for further medical care during 2000-2011 in Taiwan. In summary, 62\% of the recorded cases resulted from transport accidents and $10 \%$ from falling accidents.

the case-fatality rate during the 12 -year period but there is an obvious difference between genders. The mean case-fatality rate of the male patients was $2.1 \%$ (ranged from 1.6 to $2.6 \%$ ), and the mean case-fatality rate of the female patients was $1.6 \%$ (ranged from 1.1 to $2.0 \%$ ).

There were 36,594 cases combined with at least one of the 20 categorical injury groups listed in Table 1 ; on the other hand, only $25.8 \%$ (12,706 cases) of these pelvic fractures were of an isolated pelvic fracture pattern. Among the 20 categories of combined injuries with pelvic fractures, the most common injuries were fractures of lower limbs (cumulative incidence (ci, i.e., risk) and 95\% CI: $21.50 \%, 21.13-21.86 \%$ ), fractures of the spine/trunk $(20.97 \%, 20.62-21.33 \%)$, and fractures of upper limbs (18.18\%, 17.84-18.52\%). For other specific body regions, the common injuries were fracture of the skull or intracranial injury $(17.59 \%, 17.26-17.93 \%)$, internal injury of

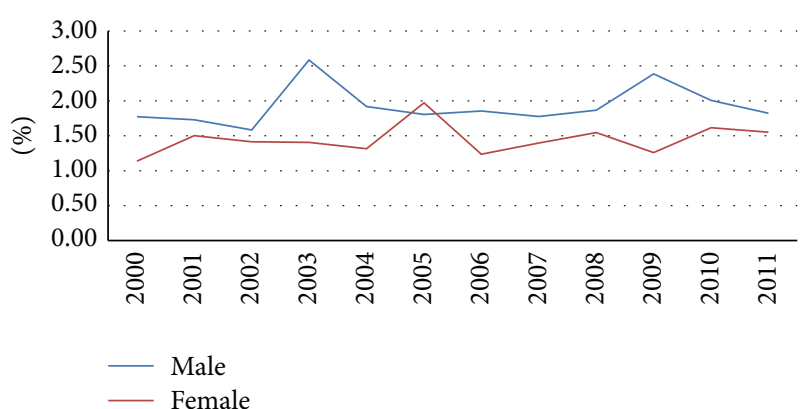

FIgURE 2: Annual mortality rate of hospitalized pelvic fractures by gender during 2000-2011 in Taiwan.

the abdomen and pelvis (11.00\%, 10.72-11.27\%), and internal injury of the chest $(7.20 \%, 6.98-7.43 \%)$. Focusing on the above six categories of combined injuries (groups 1, 2, 3, 4, 7 , and 8 ), the male patients had a higher incidence of major associated injuries with pelvic fractures than the females, especially chest internal injury (Relative Risk $(R R)=1.76)$ and abdominal/pelvic internal injury $(\mathrm{RR}=1.93)$ (Table 3$)$.

The distributions of the three pelvic fracture patterns were calculated as shown in Figure 3. The most common pelvic fracture pattern was fractures of the pubis, ilium, or ischium. Excluding unspecified fractured locations (coded as others of pelvic fractures), Table 4 compares the medical utilization between more complex types of pelvic fracture (acetabular fracture or multiple injuries with disruption of the pelvic ring) and simple types of pelvic fracture (fractures of the pubis, ilium, or ischium), revealing that a higher operation rate for pelvic fracture (44\% versus 22\%), a longer length of stay in hospital (average 17.86 days versus 12.95 days), and a greater medical expenditure (average US\$4120.86 versus US\$2678.09) were noted in the complex pelvic fracture subgroup as compared with the simple pelvic fracture subgroup. Between the complex or simple pelvic fracture patterns, 
TABle 4: Medical utilization of hospitalized pelvic fracture cases with major combined injuries in Taiwan.

\begin{tabular}{|c|c|c|c|c|c|}
\hline $\begin{array}{l}\text { Complex or simple } \\
\text { type of pelvic injury }\end{array}$ & Group of combined injury & $\begin{array}{l}\text { Summed cases } \\
2000-2011(\%)\end{array}$ & $\begin{array}{l}\text { Operation rate for } \\
\text { the pelvic injury }(\%)\end{array}$ & $\begin{array}{c}\text { Length of stay (days) } \\
\text { Mean (SD) }\end{array}$ & $\begin{array}{c}\text { Medical cost (US\$) } \\
\text { Mean (SD) }\end{array}$ \\
\hline \multirow{7}{*}{$\begin{array}{l}\text { Acetabular fracture } \\
\text { or multiple injuries } \\
\text { with disruption of } \\
\text { the pelvic ring (a) }\end{array}$} & Combined major injuries or not & & $44 \%$ & $17.86(14.31)$ & $4120.86(4902.90)$ \\
\hline & Combined with injury group-(1) & $18.12 \%$ & $39 \%$ & $16.28(14.10)$ & $3726.21(4673.87)$ \\
\hline & Combined with injury group-(2) & $15.58 \%$ & $34 \%$ & $17.10(13.98)$ & $3510.86(4457.71)$ \\
\hline & Combined with injury group-(3) & $16.11 \%$ & $45 \%$ & $16.91(12.88)$ & $3605.73(3918.62)$ \\
\hline & Combined with injury group-(4) & $28.22 \%$ & $53 \%$ & $18.62(14.29)$ & $4389.91(4961.58)$ \\
\hline & Combined with injury group-(7) & $6.40 \%$ & $42 \%$ & $19.88(14.85)$ & $5291.04(5946.72)$ \\
\hline & Combined with injury group-(8) & $8.72 \%$ & $42 \%$ & $20.30(16.70)$ & $5252.62(6166.91)$ \\
\hline ANOVA test & & & & $P=0.000$ & $P=0.000$ \\
\hline \multirow{7}{*}{$\begin{array}{l}\text { Pubic, ilium, and } \\
\text { ischium (b) }\end{array}$} & Combined major injuries or not & & $22 \%$ & $12.95(11.40)$ & $2678.09(3568.46)$ \\
\hline & Combined with injury group-(1) & $19.62 \%$ & $8 \%$ & $11.16(10.70)$ & $2217.28(3276.76)$ \\
\hline & Combined with injury group-(2) & $21.75 \%$ & $3 \%$ & $12.90(11.34)$ & $2259.66(3209.70)$ \\
\hline & Combined with injury group-(3) & $17.37 \%$ & $32 \%$ & $11.59(9.91)$ & $2216.78(2852.88)$ \\
\hline & Combined with injury group-(4) & $16.37 \%$ & $65 \%$ & $14.68(12.34)$ & $3455.27(3972.13)$ \\
\hline & Combined with injury group-(7) & $5.70 \%$ & $18 \%$ & $16.19(12.48)$ & $3998.03(4536.55)$ \\
\hline & Combined with injury group-(8) & $8.81 \%$ & $16 \%$ & $14.43(12.16)$ & $3348.78(4185.53)$ \\
\hline ANOVA test & & & & $P=0.000$ & $P=0.000$ \\
\hline
\end{tabular}

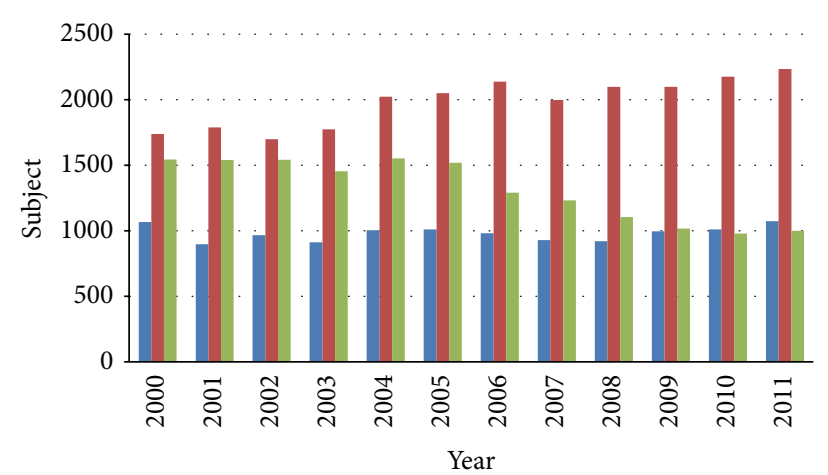

- (a) Acetabulum fracture or multiple, disruption of the pelvic ring

- (b) Fractures of pubis, fractures of ilium, or fractures of ischium

- (c) Others of pelvic fractures

FIGURE 3: Annual trends of various pelvic fracture patterns during 2000-2011. (The pelvic fractures were classified as (a) acetabulum fracture or multiple injuries with disruption of the pelvic ring; (b) fractures of the pubis, ilium, or ischium; or (c) other pelvic fractures.)

different incidences of the six major associated injuries and their effects on hospitalization days and direct medical cost were also observed, as shown in Table 4.

Among all pelvic fracture cases, the males, the younger (aged 17 years or less), and the 50 years or more groups had less opportunity to suffer any one of the above six major combined injuries. Various pelvic fractures combined with various major associated injuries were also analyzed; an extraordinary dynamic effect of age was found and lowincome population was only found to be negatively associated with fractures of the upper limbs (Table 5).
Furthermore, the percentages of operative treatments for pelvic fractures were significantly different among the three levels of hospital (26\% versus $17 \%$ versus $12 \%$ in medical centers, regional hospitals, and district hospitals, respectively; $P<0.001)$. Similarly, the percentages of operative treatments for main combined injuries (any one of injury groups (1), (2), (3), (4), (7), and (8)) were significantly different among the three levels of hospital (70\% versus 59\% versus $43 \%$ in medical centers, regional hospitals, and district hospitals, respectively; $P<0.001$ ).

To investigate whether the more severely injured patients were treated at medical centers, a logistic regression model was performed and the hospital level (medical centers versus regional/district hospitals) was used as the dependent variable. As shown in Table 6, model-a, the male patients and younger ages were positively associated with those treated at medical centers; coexistence of other major combined injuries was also easily treated at medical centers (AOR ranged from 1.23 to $2.72 ; P<0.000$ ). Furthermore, a multilevel analysis was used to evaluate the individual effects (i.e., gender, age, and presence of additional injuries) and the group effect (types of hospitals) on the inhospital deaths (Table 6, model-b); the analysis revealed that male patients with pelvic fractures had a higher risk of death than female patients $(\mathrm{AOR}=1.003 ; P<0.05)$ after adjusting for other covariates and those treated at medical centers get a higher mortality $(\mathrm{AOR}=1.01 ; P<0.01)$.

\section{Discussion}

Trauma accounts for approximately 1 in 10 deaths worldwide. The presence of a pelvic fracture increases the mortality risk [14]. In contrast to an overall decline in trauma mortality, 


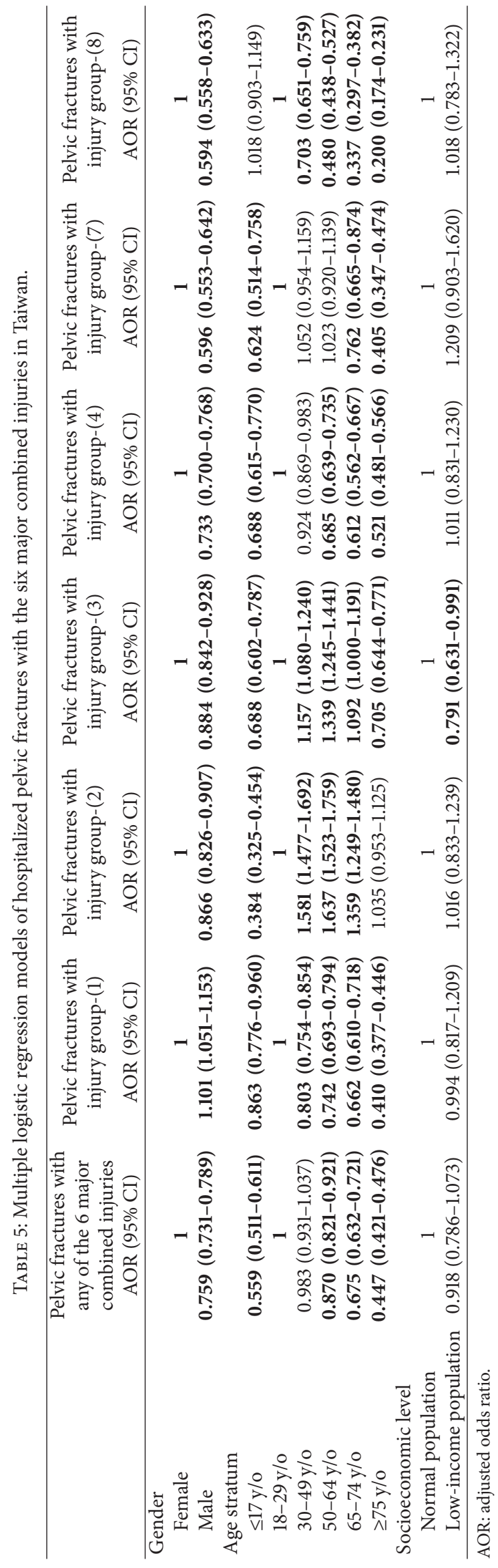


TABLE 6: Multiple logistic regression model ${ }^{\mathrm{a}}$ of treated-at-medical centers and multilevel analysis (HLM method) ${ }^{\mathrm{b}}$ of inhospital mortality among the hospitalized pelvic fractures in Taiwan.

\begin{tabular}{|c|c|c|c|c|c|c|}
\hline & \multicolumn{3}{|c|}{ Dependent variable $=$ treated-at-medical centers ${ }^{\mathrm{a}}$} & \multicolumn{3}{|c|}{ Dependent variable $=$ inhospital mortality ${ }^{\mathrm{b}}$} \\
\hline & $\beta$ value & $P$ value & AOR $(95 \% \mathrm{CI})$ & $\beta$ value & $P$ value & $\operatorname{AOR}(95 \% \mathrm{CI})$ \\
\hline Gender (male versus female) $^{*}$ & 0.151 & 0.000 & $1.116(1.116-1.211)$ & 0.003 & 0.024 & $1.003(1.000-1.005)$ \\
\hline Age (years) ${ }^{*}$ & -0.010 & 0.000 & & 0.000 & 0.004 & \\
\hline \multicolumn{7}{|l|}{ Additional injuries* } \\
\hline Simple pelvic fractures (fx) & & & 1.0 & & & 1.0 \\
\hline Pelvic fx with injury group-(1) & 0.437 & 0.000 & $1.547(1.365-1.754)$ & 0.039 & 0.000 & $1.040(1.027-1.053)$ \\
\hline Pelvic fx with injury group-(2) & 0.203 & 0.000 & $1.225(1.111-1.351)$ & 0.005 & 0.016 & $1.005(1.001-1.009)$ \\
\hline Pelvic fx with injury group-(3) & 0.341 & 0.000 & $1.407(1.287-1.539)$ & 0.004 & 0.038 & $1.004(1.000-1.008)$ \\
\hline Pelvic fx with injury group-(4) & 0.527 & 0.000 & $1.694(1.569-1.828)$ & 0.013 & 0.000 & $1.013(1.009-1.017)$ \\
\hline Pelvic fx with injury group-(7) & 0.999 & 0.000 & $2.715(2.414-3.054)$ & 0.062 & 0.000 & $1.064(1.051-1.077)$ \\
\hline Pelvic fx with injury group-(8) & 0.849 & 0.000 & $2.337(2.134-2.559)$ & 0.052 & 0.000 & $1.053(1.040-1.067)$ \\
\hline Pelvic $\mathrm{fx}$ with other injuries & -0.219 & 0.000 & $0.803(0.762-0.847)$ & 0.013 & 0.000 & $1.013(1.010-1.017)$ \\
\hline \multicolumn{7}{|l|}{ Hospital level $^{* *}$} \\
\hline District hospital & & & & & & 1.0 \\
\hline Regional hospital & & & & -0.008 & 0.000 & $0.992(0.989-0.995)$ \\
\hline Medical center & & & & 0.010 & 0.007 & $1.010(1.003-1.017)$ \\
\hline
\end{tabular}

Individual level.

${ }^{* *}$ Cluster level.

complex pelvic ring injuries remain associated with a significant risk of death [15]. In Taiwan, about $10 \%$ of annual inpatients were road traffic accident related [12] that indicated the high standing of prehospital medical care for these road injured populations in Taiwan. Some studies have highlighted the importance of effective control of haemodynamic instability to reduce the risk of mortality $[4,16,17]$. The key elements in managing patients with pelvic fractures are swift and adequate resuscitation, reversal of shock and acidosis, and rapid control of hemorrhage to facilitate survival of these patients [16]. From the viewpoint of prehospital emergency medicine, a greater proportion of pelvic fractures not of a life-threatening status, but combined with other injures need more attention and comprehensive recognition. A study that evaluated 2,176 blunt trauma patients showed that $4.5 \%$ were diagnosed with a pelvic fracture; among these cases, there were seven missed injuries upon clinical examination (a sensitivity of 93\%). This study concluded that clinical examination of the pelvis can reliably rule out significant pelvic fracture in awake and alert blunt trauma patients [18].

A previous study that reviewed 236 pelvic fracture patients showed that $64.4 \%$ were injured in motor vehicle accidents, and the average hospital stay was 16.8 days [19]. Another study including 220 men and 128 women with pelvic fractures revealed an average hospital stay of 16.5 days [20]. Similar results were found in the present study: in Taiwan, $62 \%$ of hospitalized pelvic fractures were caused by transport accidents, and the mean LOS of these patients was 17.9 days and 13.0 days for a complex and a simple fracture pattern, respectively.

A case series of 348 patients admitted due to pelvic fractures revealed that only 32 patients $(9 \%)$ had an isolated pelvic fracture [20]. In the present study in Taiwan, as high as $25.8 \%$ of hospitalized pelvic fractures were isolated pelvic fractures. Of 1,545 registered pelvic fracture cases, the incidence of abdominal injuries was $16.5 \%$, and, in severe pelvic fractures, the incidence of associated intra-abdominal injuries was $30.7 \%$ [3]. A study that included 126 patients with severe pelvic trauma ( $\mathrm{AO}$ classification type $\mathrm{B}$ or $\mathrm{C}$ ) revealed that the most common extrapelvic lesions were thoracic injuries in $56.4 \%$ and severe head injuries (GCS $<8)$ in $33.3 \%$ [6]. In the present study, associated intraabdominal injuries, thoracic injuries, and significant head injuries were found to be present in $11.0 \%, 7.2 \%$, and $17.6 \%$ of all pelvic fracture cases in Taiwan, respectively. However, greater incidences of other orthopedic fractures (including lower limb, spine/trunk, and upper limb) were noted, at $21.5 \%, 21.0 \%$, and $18.2 \%$ of all pelvic inpatients in Taiwan, respectively. This particular situation has not been reported in the literature and is worthy of further study and policy consideration.

Regression analysis was performed using data of 63,033 patients to assess the odds ratio for mortality associated with pelvic fracture and revealed that hemodynamic shock, severe head injury, and an age of sixty years or more all had an odds ratio for mortality greater than that associated with pelvic fracture [21]. In the present study, a lower casefatality rate (mean of $1.6 \%$ in females and $2.1 \%$ in males) was noted, and the emphasis of multiple regression analysis was on cases associated with other injuries, which showed that the male gender and an age of fifty years or more had a lower odds ratio for one of the major combined injuries. In Taiwan, socioeconomic status has been found to have effects on the performance of different invasive treatment methods 
for hospitalized peripheral arterial disease [22], and a low socioeconomic level population was also noted to have more opportunities to suffer a lower-limb fracture or a spine/trunk fracture among inpatients admitted due to traffic accidents [12]. In the present study, the low-income population was only found to be significantly negatively associated with upper limb fractures when the patients suffered a pelvic fracture.

The NHIB has established a uniform system to control the quality of medical services and coding. If the medical services provided to beneficiaries by the contracted medical care institution are determined by the Professional Peer Review Committee to be incompatible with the provisions of the NHI Act, the expenses thereof are borne by the contracted medical care institution themselves. Otherwise, the Disputes Settlement Board, established under the NHI scheme, settles disputes arising in cases approved by the insurer and raised by the insured, group insurance applicants, or contracted medical care institutions. Based on the above, the quality of data acquisition of the present study would be reliable. However, about 1 third of these pelvic fractures were not accurately classified that made a drawback of the present study.

\section{Conclusion}

The incidence of admission for pelvic fractures was low, and an increasing trend with age was noted in Taiwan. In general, the case-fatality rate of Taiwanese pelvic fractures was lower than those of other countries, and three-quarters of cases were combined with other injuries. The most common associated injuries in an identified body region were other orthopedic fractures of lower limbs, the spine/trunk, or upper limbs, followed by significant head injuries, intra-abdominal injuries, and thoracic injuries. Among the hospitalized pelvic fracture cases, the male patients and younger ages were positively associated with those treated at medical centers, and coexistence of major combined injuries was also easily treated at medical centers.

\section{Conflict of Interests}

All authors declare that there is no conflict of interests, including directorships, stock holding, or contracts.

\section{Authors' Contribution}

The study was designed by Nan-Ping Yang, Nien-Tzu Chang, and Yi-Hui Lee; data were gathered and analyzed by Yu-Zhen Lin, Kai-Biao Lin, Ching-Hsiao Yu, and I-Liang Yu; the initial draft of the paper was written by Nan-Ping Yang, Chien-Lung Chan, and Yi-Hui Lee; the accuracy of the data and analyses was assured by Nan-Ping Yang, Chien-Lung Chan, Dachen $\mathrm{Chu}$, and Nien-Tzu Chang. All authors participated in the preparation of the paper and approved the final version. All authors have read and approved the final paper. In general, Yi-Hui Lee, Nien-Tzu Chang, and Nan-Ping Yang contributed equally to this work.

\section{Acknowledgment}

The authors would like to thank Taoyuan General Hospital for supporting the study (Grant no. PTH10301).

\section{References}

[1] O. Hauschild, P. C. Strohm, U. Culemann et al., "Mortality in patients with pelvic fractures: results from the German pelvic injury register," Journal of Trauma-Injury, Infection and Critical Care, vol. 64, no. 2, pp. 449-455, 2008.

[2] T. Pohlemann, H. Tscherne, F. Baumgärtel et al., "Pelvic ring injuries: epidemiology, theraphy and long terme course. Review of the multicenter of the German Pelvis Group," Unfallchirurg, vol. 99, no. 3, pp. 160-167, 1996 (German).

[3] D. Demetriades, M. Karaiskakis, K. Toutouzas, K. Alo, G. Velmahos, and L. Chan, "Pelvic fractures: epidemiology and predictors of associated abdominal injuries and outcomes," Journal of the American College of Surgeons, vol. 195, no. 1, pp. $1-10,2002$.

[4] B. J. Gabbe, R. de Steiger, M. Esser, A. Bucknill, M. K. Russ, and P. A. Cameron, "Predictors of mortality following severe pelvic ring fracture: results of a population-based study," Injury, vol. 42, no. 10, pp. 985-991, 2011.

[5] J. H. Holstein, U. Culemann, and T. Pohlemann, "What are predictors of mortality in patients with pelvic fractures?" Clinical Orthopaedics and Related Research, vol. 470, pp. 20902097, 2012.

[6] A. Siegmeth, T. Müllner, C. Kukla, and V. Vécsei, "Accompanying injuries in severe pelvic trauma," Unfallchirurg, vol. 103, no. 7, pp. 572-581, 2000 (German).

[7] D. Demetriades, M. Karaiskakis, G. C. Velmahos, K. Alo, J. Murray, and L. Chan, "Pelvic fractures in pediatric and adult trauma patients: are they different injuries?" Journal of Trauma-Injury, Infection and Critical Care, vol. 54, no. 6, pp. 1146-1151, 2003.

[8] S. Sauerland, B. Bouillon, D. Rixen, M. R. Raum, T. Koy, and E. A. M. Neugebauer, "The reliability of clinical examination in detecting pelvic fractures in blunt trauma patients: a metaanalysis," Archives of Orthopaedic and Trauma Surgery, vol. 124, no. 2, pp. 123-128, 2004.

[9] N. Yang, Y. Lee, C. Lin, Y. Chung, W. Chen, and P. Chou, "Utilization of and direct expenditure for emergency medical care in Taiwan: a population-based descriptive study," Journal of Epidemiology, vol. 19, no. 1, pp. 41-48, 2009.

[10] "Introduction of Taiwan's emergent-critical hierarchical system (Chinese version)," http://www.tjcha.org.tw/FrontStage/page .aspx?ID=FF2E2252-F2AA-4573-9D7A-A00152BA9A63.

[11] "Taiwan NHI Information for the public: essential data of ensured affair," http://www.nhi.gov.tw/webdata/webdata.aspx? menu=17\&menu_id=661\&WD_ID=689\&webdata_id=805.

[12] R. H. Pan, N. T. Chang, D. Chu et al., "Epidemiology of orthopedic fractures and other injuries among inpatients admitted due to traffic accidents: a 10 years nationwide survey in Taiwan," The Scientific World Journal, vol. 2014, Article ID 637872, 7 pages, 2014.

[13] A. V. Diez-Roux, "Multilevel analysis in public health research," Annual Review of Public Health, vol. 21, pp. 171-192, 2000.

[14] S. Frevert, B. Dahl, and L. Lönn, "Update on the roles of angiography and embolisation in pelvic fracture," Injury, vol. 39, no. 11, pp. 1290-1294, 2008. 
[15] T. Pohlemann, D. Stengel, G. Tosounidis et al., "Survival trends and predictors of mortality in severe pelvic trauma: estimates from the German Pelvic Trauma Registry Initiative," Injury, vol. 42, no. 10, pp. 997-1002, 2011.

[16] K. Eckroth-Bernard and J. W. Davis, "Management of pelvic fractures," Current Opinion in Critical Care, vol. 16, no. 6, pp. 582-586, 2010.

[17] C. C. Burlew, E. E. Moore, W. R. Smith et al., "Preperitoneal pelvic packing/external fixation with secondary angioembolization: optimal care for life-threatening hemorrhage from unstable pelvic fractures," Journal of the American College of Surgeons, vol. 212, no. 4, pp. 628-635, 2011.

[18] R. P. Gonzalez, P. Q. Fried, and M. Bukhalo, "The utility of clinical examination in screening for pelvic fractures in blunt trauma," Journal of the American College of Surgeons, vol. 194, no. 2, pp. 121-125, 2002.

[19] G. V. Poole, E. F. Ward, F. F. Muakkassa, H. S. H. Hsu, J. A. Griswold, and R. S. Rhodes, "Pelvic fracture from major blunt trauma: outcome is determined by associated injuries," Annals of Surgery, vol. 213, no. 6, pp. 532-538, 1991.

[20] G. V. Poole and E. F. Ward, "Causes of mortality in patients with pelvic fractures," Orthopedics, vol. 17, no. 8, pp. 691-696, 1994.

[21] A. K. Sathy, A. J. Starr, W. R. Smith et al., "The effect of pelvic fracture on mortality after trauma: an analysis of 63,000 trauma patients," Journal of Bone and Joint Surgery A, vol. 91, no. 12, pp. 2803-2810, 2009.

[22] N. T. Chang, C. L. Chan, Y. T. Lu et al., "Invasively-treated incidence of lower extremity peripheral arterial disease and associated factors in Taiwan: 2000-2011 nationwide hospitalized data analysis," BMC Public Health, vol. 13, article 1107, 2013. 


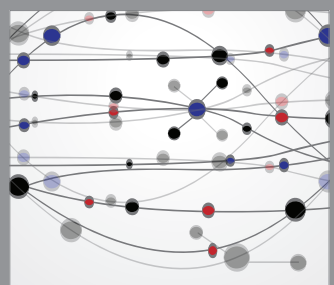

The Scientific World Journal
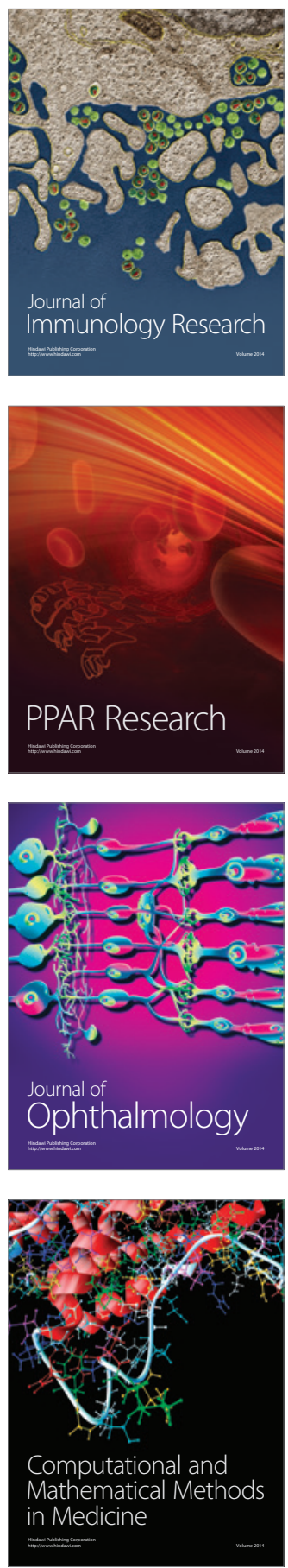

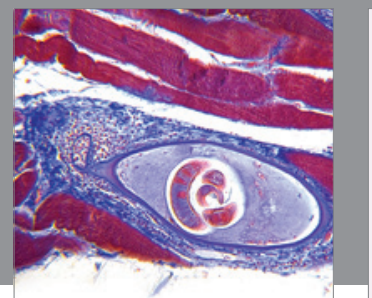

Gastroenterology

Research and Practice
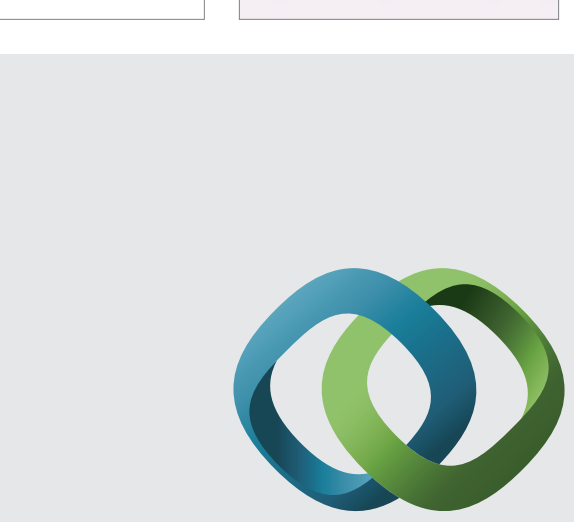

\section{Hindawi}

Submit your manuscripts at

http://www.hindawi.com
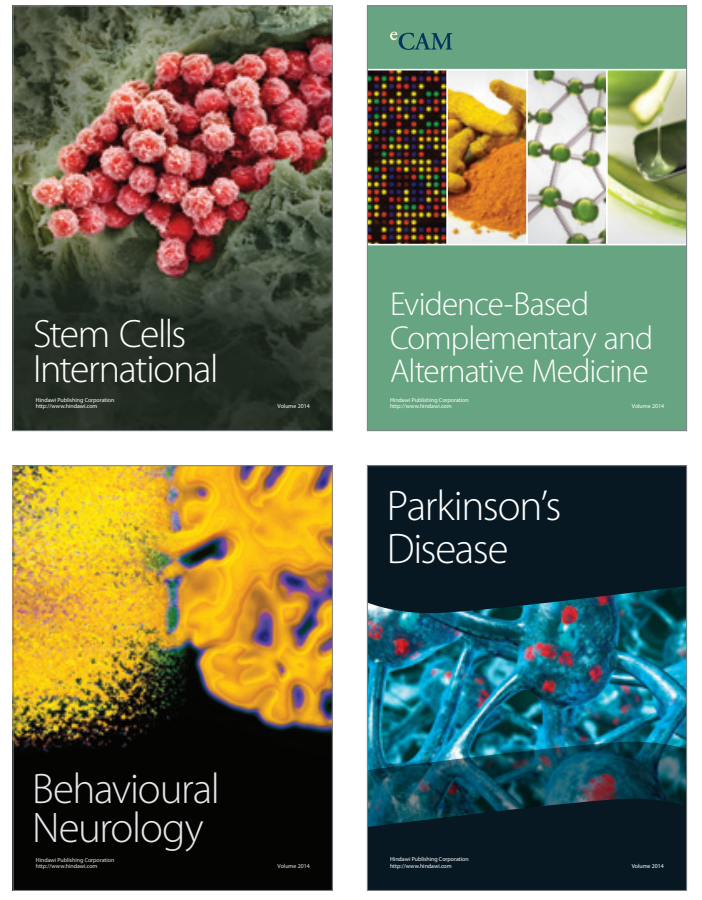
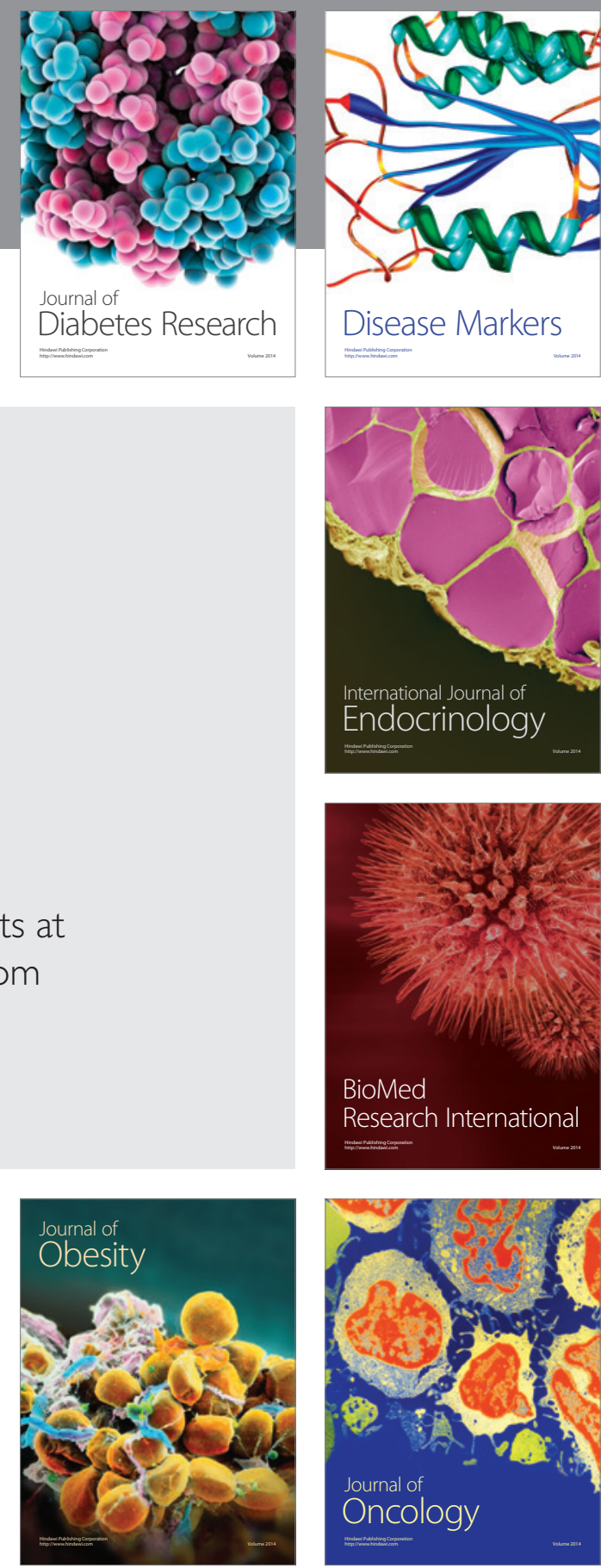

Disease Markers
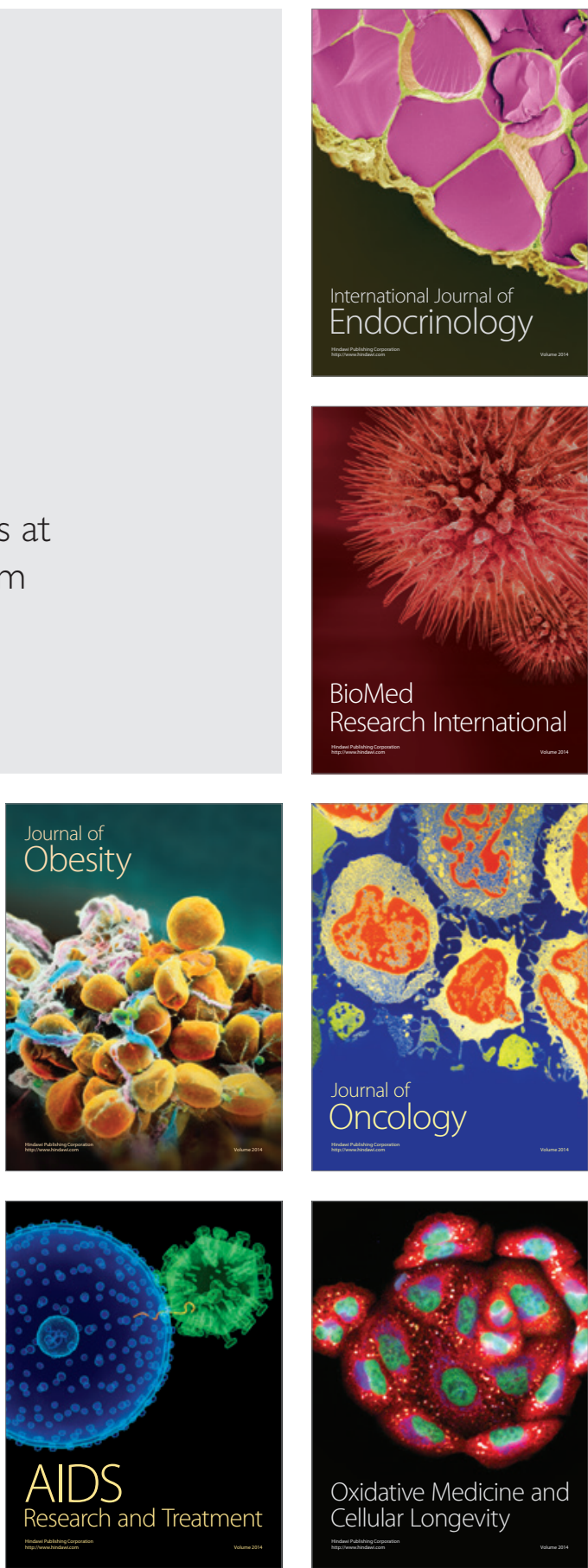